\title{
Benchmarking regional innovative performance: Composite measures and direct innovation counts
}

ARTICLE in SCIENTOMETRICS · JANUARY 2013

Impact Factor: 2.18 · DOI: 10.1007/s11192-012-0753-2

CITATIONS

2

2 AUTHORS:

Teemu Makkonen

University of Surrey

21 PUBLICATIONS 17 CITATIONS

SEE PROFILE
READS

32
Robert Van der Have

Aalto University

13 PUBLICATIONS 16 CITATIONS

SEE PROFILE 


\title{
Benchmarking regional innovative performance: Composite measures and direct innovation counts
}

Teemu Makkonen ${ }^{1}$ and Robert van der Have ${ }^{2}$

${ }^{1}$ Department of Geosciences and Geography, University of Helsinki, P.O. Box 64, FI-00014,

University of Helsinki, Finland. Tel. +358 9191 50794, Fax +358 9191 50760, E-mail:

teemu.makkonen@helsinki.fi

${ }^{2}$ VTT Technical Research Centre of Finland, Organizations, Networks and Innovation Systems, P.O. Box 1000, FI-02044 VTT, Finland; and Institute of Strategy, Department of Industrial Engineering and Management, School of Science, Aalto University, Finland.

This is an Accepted Manuscript of an article published by Springer in Scientometrics on 01 May 2012, Vol. 94 No. 1, pp. 247-262. The final publication is available at Springer via http://dx.doi.org/10.1007/s11192-012$\underline{0753-2}$

\begin{abstract}
There is a considerable amount of discussion, but still no consensus, about which indicator should be used to measure innovation. To participate in this debate, a unique innovation database, SFINNO, is introduced. Innovation counts from the database are used as the baseline, to which individual proxy indicators (patent- and research and development statistics) of innovation and innovation indexes, constructed here with principal component analysis, are compared. The local administrative units of Finland serve as the regional units benchmarked. The study results show that innovation is a complex phenomenon which cannot be entirely explained through the use of proxy statistics, as the linkages between innovation input- and output-indicators are fuzzy. We also show that the strength of these linkages varies by field of technology. Furthermore, different innovation measures produce highly divergent rankings when they are used as benchmarking tools of regional innovative performance. Although the produced innovation indexes perform slightly better, their superiority is marginal. Therefore, caution should be taken before drawing too drastic policy conclusions depending on a single measure of regional innovative performance.
\end{abstract}

Keywords Innovation; Indexes; Patents; R\&D, Regional innovative performance
MSC $62 \mathrm{H} 25 ; 62 \mathrm{H} 20$
JEL O18; O30; R11 


\section{Introduction}

For more than two decades, there has been great interest in both academia and public policy in the role of the regional, local or territorial environment for innovation by firms. Based on modern economic theory, innovation has been given an important role in economic geography and regional science as an explanation of the organization of economic activity in space, and the growth and stagnation of regions over time (e.g. Acs 2002; Acs and Varga 2002). The importance of the phenomenon of innovation is also evidenced in the publication trends of scientific articles in the fields of economics, management and business, and geography that have innovation as their topic (Fagerberg and Verspagen 2009).

Many researchers of innovation acknowledge that innovative activity is very complex, and consequently hard to measure. This complexity of the phenomenon of interest therefore creates a big challenge for researchers who try to understand its determinants. Illustrative of this is the debate on whether and how geographically mediated knowledge spillovers can be measured. Jaffe (1989), who pointed to the public good character of knowledge, detected a positive effect of knowledge generation in universities on the inventive output (measured by patents) of firms at the state-level. Subsequent, Acs et al. (1992) replicated Jaffe's study by comparing the results acquired by Jaffe's use of a patent-measure to those acquired by using a direct measure of innovation counts. Their results reinforced those of Jaffe, but found an impact of university spillovers no less than twice as strong on innovations as on patented inventions, and also a much stronger proximity effect of spillovers than Jaffe was able to detect with patent data. Clearly, the type of proxy one chooses to measure innovation with can greatly affect the substantive conclusions of research, or the information on which public policy-makers base decision-making (e.g. the ranking of territorial units by their level of innovative activity). This realization has led to the adoption of different measures of innovation over time, starting with the use of patent statistics (Schmookler 1950), followed by research and development (R\&D) expenditures (Griliches 1984), and eventually dedicated innovation surveys adopting a broader conceptualization (OECD 1992).

These changes have been driven by the changing view of what constitutes innovation, because theories are needed to interpret data, and theoretical developments may call for different types of data (see e.g. Smith 2005). As newer theories, emphasizing the systemic and complex 
nature of innovation, emerged in the late 1980s (Kline and Rosenberg 1986) and 1990s (Rothwell 1992), the theoretical rationale for science, technology and innovation (STI) policies changed as well, increasingly emphasizing the complex set of links between R\&D activities and the broader innovation process (Molas-Gallart and Davies 2006). Recognizing this 'breadth' of innovative activity and variety of innovation outcomes, a recent development in innovation measurement has been the introduction of so-called composite measures, which recognize the incompleteness of individual measures alone, and essentially treat the innovation concept as not directly observable but latent (e.g. Hagedoorn and Cloodt 2003). To achieve improved measurement validity, composite innovation indexes (CII's) are therefore composed of multiple measures or indicators.

Yet, despite the prominence of this development in theory and policy, descriptive bibliometric analysis reveals that there are surprisingly few works that deal explicitly with the question of how well this newer class of CII's performs, with just a hand full of serious investigative studies published in recent years. In addition, nearly all of the critical articles we surveyed deal with the use of CII's either on the level of single organizations (firms) or on the level of nations, while to the best of our knowledge only a few works exist that looks at CII's measured on the level of regions (also Slaper et al. 2011). It is important to fill this gap because of the prominence of innovation in economic geography and regional science, which in turn strongly influenced public policy making for the benefit of regional innovation and growth performance (e.g. de Bruijn and Lagendijk 2005; Varga 2006). One of the major obstacles involved in assessing the performance of CII's, is the scarce availability of reliable 'benchmark' measures of innovation. In this paper, we apply one such possible benchmark measure: a unique and comprehensive longitudinal and geospatial database of direct innovation counts.

In this paper we perceive an innovation broadly as a new product, service or process (or a significant enhancement thereof). That is, as a distinction from inventions only, originally made by Schumpeter (1934), an innovation must be successfully introduced on the market. We recognize that this is, however, only the starting point and quite a simplistic way of looking at innovation. Innovation can be defined in numerous other ways and there is a whole range of innovation typologies ranking from the novelty of innovation (incremental, radical etc.) to classification of innovation types (including e.g. organizational and marketing innovations). The issue of 
innovation quality is, however, beyond the scope of our study, and our aim here is to be inclusive to various kinds of innovations.

Thus, the main question this paper addresses is: how can innovation be validly measured for regions, which as we pointed out above, is a vital point when innovation studies are being used as the basis for STI policy making. To go about this question the most common proxy variables for innovation - patent- and R\&D statistics - are included in our study. Furthermore, as the need to use measures relating to more than one aspect of innovation has long been recognized (e.g. Damanpour 1991), the feasibility of synthetic measures accommodating this is tested by construction of composite innovation indexes by means of principal component analysis. In doing so, we test the applicability of different proxy indicators and composite indexes of innovation as a regional benchmarking tool. It is important to assess the effects of possible disparities between indicators, not in the least because the most widely used indicators (patens and R\&D expenditures) tend to under-present young and small firms - which are known to be important innovators. Furthermore, and not all patents are commercialized, which makes patent analysis vulnerable to upward bias in the context of regional benchmarking.

To gain a better insight in these issues, we study the local administrative units (LAU-1) of Finland over a ten-year period as our test case, using unique and comprehensive historical count data of new product announcements from the SFINNO database of Finnish innovations (see Palmberg et al., 1999). We use this unique data as our baseline for the innovative performance of regions. In the following section, we review the existing literature on patent- and R\&D statistics, innovation count data, as well as CII's. Section 3 will then introduce our data and research methods in more detail, after which we outline our results in detail in section 4 . The paper concludes with a discussion.

\section{Literature review}

Patent and $R \& D$ statistics

The basic argument behind the use of $R \& D$ and patent statistics as a proxy for innovation in regions is that an increase in the $\mathrm{R} \& \mathrm{D}$ efforts of a region will result in a higher rate of invention. In turn, a higher number of patents is assumed to lead to more innovations in that region. 
However, this linear relationship is elusive, and both of these measures, as well as other less frequently applied measures such as licences, science publications, service- or trademarks, and utility models have their shortcomings as indicators of innovation (Beneito 2006; Mendonça et al. 2004; Nelson 2009; Schmoch and Gauch 2009).

The limitations of $R \& D$ statistics stem mainly from the fact that not all R\&D efforts are necessarily related to successful, or commercialized innovation outputs (Gu and Tang 2004; Nelson 2009). For example, because technological progress can be cumulative in nature for prolonged periods of time, R\&D activity may be performed strategically to 'occupy' a technology area and raise the cost of catching up, thus creating barriers to entry which deter potential new rivals (Lieberman 1989; Perez and Soete 1988). Also, R\&D is merely an input factor of innovation and only one out of several inputs, such as design, trial production, market analysis, training, etc. (Kleinknecht et al. 2002; Ratanawaraha and Polenske 2007). Lastly, certain sectors as well as micro firms and small firms tend to be underrepresented in R\&D data (van der Panne and van Beers 2006).

Patents, on the other hand, have been commonly used to depict the output side of innovation. However their weakness as an indicator of innovation is very much related to that of R\&D data; not all patented inventions become innovations (Coad and Rao 2008; Gu and Tang 2004). Furthermore, the innovative content and economic value of patents may differ greatly among them (Beneito 2006; Kleinknecht et al. 2002).

In addition, an undesired complication of patent data is the fact that some technological sectors patent more than others. Certain other sectors, such as services and software, are generally poorly suitable for patenting and thus patents mainly cover product-type innovations (Camacho and Rodríguez 2005; Hipp and Grupp 2005). Also firm-size affects the propensity to patent, for example due to economies of scale (Acs et al. 1992; Arundel and Kabla 1998). The latter fact implies that the spatial distribution of large and small firms may distort the measured regional innovativeness when approximated through patents, and the former implies that a mere spatial pattern of industrial or sectoral specialization may disfigure regional innovativeness when applying a patent measure. This is clearly undesirable when informing public policy. A third drawback of the patent measure of innovation is the fact that in addition to firm- and technologysector level characteristics, also the characteristics of innovations themselves have been found to 
influence firms' decision to patent innovations or not. Studying the same Finnish innovation database we rely on in the present study, Mäkinen (2007) finds that in addition to technology, firm and market attributes, also characteristics of innovations themselves, such as their degrees of novelty and complexity, significantly affect the decision to apply for a patent. A patent measure therefore obscures potentially interesting information on some types of innovations.

On the positive side, patents are issued only for novel inventions, which means that very minor innovations or modest adaptations will not be counted since such innovation are not patentable (Fagerberg and Srholec 2008; Hall et al. 2005). On the other hand, only very recently, a new issue in this context has been raised by the OECD (2011). Namely, a newly constructed measure of the quality of patents in various dimensions suggests that patent quality has in fact fallen drastically between the 1990 s and 2000 s, on average by $20 \%$ in every major economy. To the extent that valuable patents are more associated with meaningful innovations, as opposed to minor improvements, this raises a serious question whether the statistical link between patents and true innovations has been complicated over time. Moreover, firms can use other means of appropriation besides patents, such as secrecy, lead time etc., to protect their intellectual property (Arundel 2001; Gu and Tang 2004). Finally, there are differences in the requirements of patentability on national and regional levels, which can in extreme cases lead to a situation where a patent is granted in one country or region but rejected in another (Michel and Bettels 2001). It has also been found less clear where firms place their patents (domestically or abroad) (Unger 2000).

Regardless these issues, $\mathrm{R} \& \mathrm{D}$ and patent statistics have been and still are in frequent use and in fact, by certain standards, Hagedoorn and Cloodt (2003) as well as Gössling and Rutten (2007) have shown that statistically it does not make much difference which of these indicators of innovation are used: both $R \& D$ and patents are still seen as valid indicators of (technological) innovation (see also Acs et al. 2002). In conclusion, we can say that although both of these indicators have their drawbacks they can still contain useful information on the innovative activities of firms. 
Another way of measuring innovation is the use of composite innovation indexes (CII's), which were first introduced in the 1990s for firm-level measurement of innovation. As there are many innovation indicators, researchers have argued that each individual indicator is just a partial indication of the total realized innovation effort of a subject. Therefore, some pioneering authors stated that innovation indexes are superior to any single innovation variable (e.g. Hollenstein 1996). The logic behind this reasoning is that innovation is not a single state, but an ongoing process consisting of different phases. Proponents of CII's therefore advocate the use of input and output factors simultaneously (Booysen 2002; Carayannis and Provance 2008). Therefore, the use of indexes is seen as an appropriate way of synthesizing the information provided by several indicators into one combined measure (Coad and Rao 2008; Tang and Le 2007). In short, composite indexes are a good way to: 1) synthesize complex or latent constructs, 2) provide the 'bigger picture', 3) attract public interest and 4) reduce the size of information (Saisana et al. 2005). Therefore, innovation indexes should provide a more comprehensive way to benchmark the innovative performance of regions for the purpose of policy-making.

There are many examples of firm-level as well as regional and national innovation or science- and technology (S\&T) indexes in previous literature. These indexes have been constructed from a variety of measures, broadly divided between measures of inventive or innovative activity, and measures that capture the preconditions, or the capacity for innovative activity. Table 1 summarizes the most commonly used measures to construct these indexes. Commonly employed methods of constructing these indexes include e.g. factor analysis (Buesa et al. 2010; Pinto 2009), principal component analysis (Kaasa 2009), fuzzy set theory (Moon and Lee 2005) and data envelope analysis (Zabala-Iturriagagoitia et al. 2007). A number of studies (Archibugi and Coco 2005; Grupp and Mogee 2004; Grupp and Schubert 2010) have however raised concerns in relation to the use of innovation and S\&T indexes on a regional level: even well-accepted methods to construct indexes can lead to drastically different results. Therefore, indexes can produce highly divergent rankings as the construction of indexes involves a subjective choice of method and variables, which is also a question of data availability and as such is performed in an ad hoc manner (Booysen 2002; Saisana et al. 2005). As a result, the number of 
different innovation measures has increased drastically and the indexes produced by e.g. statistical offices, public administration, and academic research units have become quite divergent (Lepori et al. 2008). In summary, innovation indexes: 1) can potentially send non-robust policy messages, 2) simplify policy conclusion and 3) increase the quantity of required data (Saisana et al. 2005). Thus, although indexes might appear at first glance to be a sophisticated way to measure innovation, there are also limitations to them, which should be taken into account when used as a regional benchmarking tool. 
Table 1 Overview of employed measures to construct CII's (or latent dimensions)

\begin{tabular}{|c|c|c|c|c|c|c|c|c|c|c|c|c|}
\hline $\begin{array}{l}\text { Indicators/derived indicators } \\
\text { by type and study: }\end{array}$ & $\begin{array}{c}\text { Feeny \& } \\
\text { Rogers } \\
(2003) \\
\end{array}$ & $\begin{array}{c}\text { Gu \& } \\
\text { Tang } \\
(2004) \\
\end{array}$ & $\begin{array}{c}\text { Moon \& } \\
\text { Lee } \\
(2005) \\
\end{array}$ & $\begin{array}{c}\text { Buesa } \\
\text { et al. } \\
(2006)^{1} \\
\end{array}$ & $\begin{array}{c}\text { Tang \& } \\
\text { Le } \\
(2007) \\
\end{array}$ & $\begin{array}{c}\text { Zabala-I } \\
\text { et al. } \\
(2007) \\
\end{array}$ & $\begin{array}{c}\text { Coad \& } \\
\text { Rao } \\
(2008) \\
\end{array}$ & $\begin{array}{c}\text { Fagerberg } \\
\& \text { Srholec } \\
(2008)^{1}\end{array}$ & $\begin{array}{l}\text { Kaasa } \\
(2009)^{1}\end{array}$ & $\begin{array}{l}\text { Pinto } \\
(2009)^{1}\end{array}$ & $\begin{array}{c}\text { Buesa } \\
\text { et al. } \\
(2010)^{1} \\
\end{array}$ & $\begin{array}{c}\text { Pinto \& } \\
\text { Guerreiro } \\
(2010)^{1}\end{array}$ \\
\hline \multicolumn{13}{|l|}{ Innovation measures } \\
\hline$R \& D$ & $x$ & $x$ & $x$ & $x$ & $x$ & $x$ & $x$ & & $x$ & $x$ & $x$ & $x$ \\
\hline Patents & $x$ & $x$ & $x$ & & $x$ & $x$ & $x$ & $x$ & $x$ & $x$ & & $x$ \\
\hline Innovations (product and process) & & & & & $x$ & & & & & & & \\
\hline Designs and trademarks & $x$ & & & & & & & & & & & \\
\hline Scientific papers and certifications & & & $x$ & & & & & $\mathrm{x}$ & & & & \\
\hline \multicolumn{13}{|l|}{ Capacity measures } \\
\hline Industrial engineering & & & & & $x$ & & & & & & & \\
\hline Human capital $^{2}$ & & $x$ & $x$ & $x$ & & $x$ & & $x$ & $x$ & $x$ & $x$ & $x$ \\
\hline Infrastructure & & $x$ & & $x$ & & & & $x$ & & & $x$ & \\
\hline Economic and labour market variables & & & $x$ & $x$ & & & $x$ & $x$ & & & $x$ & $x$ \\
\hline Social variables ${ }^{4}$ & & & & & & & & $\mathrm{x}$ & & & & \\
\hline Indicators included in the analysis & 4 & 5 & 11 & 28 & 6 & 7 & 6 & 24 & 9 & 15 & 21 & 30 \\
\hline
\end{tabular}

1 other components/factors besides innovation capacity/performance were also constructed

${ }^{2}$ e.g. population with tertiary education, employment in high technology industry, life-long learning etc.

${ }^{3}$ e.g. product sales, high technology exports, GDP per capita, employment rate etc.

${ }^{4}$ e.g. indexes on political competitiveness and corruption etc. 


\section{Direct innovation output measures}

Direct quantification of the innovative output of companies is one important way to measure the innovative activity in regions. Most commonly, direct information about innovations is gathered through questionnaires, inquiring firm representatives to indicate the number of newly introduced products/services or their share of sales during a fixed period of time. Since the surveyed firms are the subject of inquiry, this approach is in methodological terms also referred to as the 'subjectapproach' in the field of quantitative innovation studies (OECD 1992). Due to its broad coverage and wide availability, the subject-approach is still the dominant approach today. The Community Innovation Survey (CIS), which is executed by national statistical offices throughout the European Union, is a well-known example of this approach.

In the literature on innovation measurement there are a number of shortcomings listed for with such aggregate, firm-level innovation data collected with questionnaires: 1) they are not completely objective as the respondent decides what an innovation is (Ratanawaraha and Polenske 2007), 2) indicators from surveys sometimes suffer from estimated answers and low response rates, as the burden is placed on responding firms to provide data, which may hamper regional comparisons (Kleinknecht et al. 2002), 3) the technological novelty and economic value of reported innovations can be extremely heterogeneous (Rothwell and Gardiner 1988) and 4) innovation output measures are expensive to produce and the data availability is limited (Acs et al. 2002). Nevertheless, innovation surveys measure directly the output side of innovation by asking about new or significantly improved products, services or processes, which is something that, strictly speaking, cannot be said about the measures previously discussed in this paper. Thus, innovation surveys offer valuable information about the innovative performance of regions.

In contrast, the 'object approach' (OECD 2005) takes a specific innovation (defined as a new, or significantly improved product or service introduced to the market) as point of departure by counting and recording individual innovations. Possibly, more information can be collected about the related innovator as well (e.g. firm size). Dealing directly with the output (i.e. the introduction of a new product or service after a discrete innovation process), it can provide more detailed information on the characteristics of the innovation itself, the underlying knowledge-base, its origin and development (Palmberg et al. 1999). Here, some similarities are shared with patent analysis, but a main difference is that although counting pure innovations only (where patent 
analysis counts inventions, and not necessarily innovations), the object approach cannot cover the universe of innovations introduced to the economic system, as this is unobservable (Archibugi and Pianta 1996). Hence, due to differences in the likelihood of being picked up in the research environment between heterogeneous innovations, a degree of bias toward innovations that are perceived to be relevant exists. The reason for this 'significance bias', is that the information sources that are used to identify innovations, such as trade journals or industry expert opinions, tend to report only more significant innovations. On the other hand, the opposite has been argued for subject-based surveys because of the subjective evaluation of 'innovativeness' (Ratanawaraha and Polenske 2007).

Due to its reliance on public information sources, the object-based approach is in methodological terms referred to as literature-based innovation output (LBIO) method (Coombs et al. 1996, van der Panne 2007). One important advantage for our purposes of LBIO data is that new products announced in professional journals are in principle assigned to the unit that brings the innovation to the market, which makes the data suitable for research on the spatial distribution of innovation (Kleinknecht et al. 2002).

\section{Data and methods}

Data

In this paper variables concerning R\&D activity, (R\&D spending and -personnel) and patenting, (patent applications and patents granted), are utilized as individual indicators of innovation and to construct innovation indexes. The data covers the 74 (according to division of 2006) of the level-1 Local Administrative Units (LAU-1) of Finland plus the province of Åland as a whole (due to missing data on the LAU-1 level in Åland). LAU-1 regions were chosen as the level of analysis for three reasons. First, LAU-1 regions, which function as areas of daily commuting, are socioeconomically coherent groups of municipalities usually containing a central town and surrounding smaller municipalities. Second, the availability of regional data in LAU-1 level is significantly more extensive for the lower municipality level (LAU-2), facilitating more stable and meaningful observations. On the other hand, it offers more units of observation than the significantly larger NUTS-3 areas. The data was gathered for the 10-year period 1997-2007. The averages of these years are used as a starting point for the analysis. The R\&D and patent data was compiled from the 
official Statistics Finland databases (StatFin). The missing data on certain LAU-1s on individual years were estimated as moving averages of contiguous years. The data values are normalized by population (Table 2). We sub-divided our patent data according to the International Patent Classification (IPC) system into the eight sections that comprise the highest hierarchical level in order to gain more insight as to whether results may vary by field of technology. We chose to do the region-IPC cross-classification at this level of the IPC hierarchy to limit small numbers of observations. R\&D data was additionally divided into government- and private R\&D, as government funded R\&D was posited to have a weaker link to commercialized innovations compared to private R\&D (see Beard et al. 2009).

Table 2 The chosen variables depicting innovation in this study

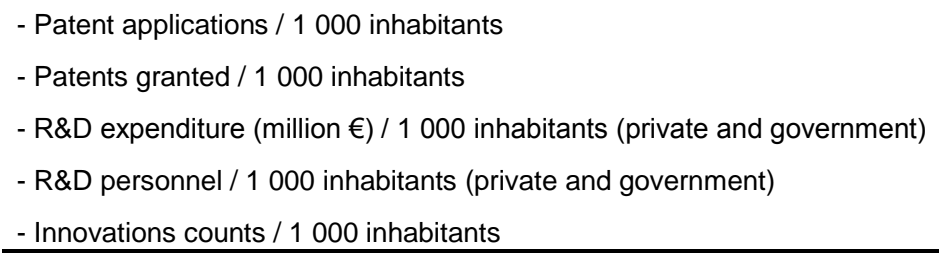

Our innovation count data serves as our baseline for the innovative performance of Finnish regions, and is drawn from the SFINNO database of Finnish innovations which is compiled by the Group for Innovation Studies at the Technical Research Centre of Finland (VTT). Compilation of SFINNO has been done via a longitudinal LBIO-method. As a starting point for identification, an 'innovation' has been defined as an invention that has been commercialised on the market by a business firm or the equivalent, in line with the guidelines set out in the OECD's Oslo Manual (1992). As a minimum requirement for inclusion an innovation has had to pass successfully through the development and prototype phases, having seen at least a major market transaction. A second requirement for an innovation to be included in the database has been that it had to be a technologically new or significantly enhanced product compared with the firm's previous products. The data comprises only innovations that have been commercialized by firms registered as domestic in Finland. The SFINNO database follows the 'object' orientation, using the innovation itself as the starting point of capturing information by direct identification from a range of publicly available sources. This limits some forms of bias, such as observed innovativeness, and firm-size and industry distributions which are associated with other commonly used innovation measures such as patents, $R \& D$ data and self-reported innovation-questionnaires. 
Three types of sources for the identification of innovations have been combined: expert opinion, and systematic reviews of trade and technical journals as well as annual reports of large R\&D spending firms. Similar procedures of collecting innovation data have also been used in other object-based innovation data collection efforts that are similar in nature to SFINNO (e.g. Acs and Audretsch 1993; Coombs et al. 1996; Edwards and Gordon 1984). The volumes of a 22-year period (data from the years 1997-2007 were used in this paper) for a total of 18 different technical and trade publications have been systematically reviewed to identify new product introductions from companies over a broad range of Finnish industries over time. Only edited articles dealing with the introduction of new products, which conformed to our definitions and criteria for an innovation, were considered in the data collection process, because the editor's expert opinion assures that the innovations are sufficiently novel to be reported. As such, simple listings and advertisements were ignored to assure a more objective measure of innovativeness. Researchers listed all counted innovations, and carefully compared lists to avoid double-counting before lists were added to the database. The commercializing firm has also been identified from the articles, allowing collection of basic firm data such as firm size, age and - important for our purposes - the location where development took place. These additional data were collected from the joint business information system of the National Board of Patents and Registration and the Finnish Tax Administration, as well as the Business Register maintained by the national statistical office Statistics Finland.

A crucial step in compiling our dataset for this study was to assign the correct geographical 'home region' to innovations. To ensure reliable geotagging, we undertook three steps. First, we incorporated the municipal location of main innovation development from the available selfreported questionnaire data, directly obtained from the innovators. For the remaining innovations for which no questionnaire data was available due to non-response, we assigned the headquarterlocation instead in the case of small- and medium-sized companies, as these typically bundle their core activities in one place. For the remaining large-firm innovations for which no questionnaire data was available, we carefully examined their R\&D units on a case-by-case basis. For firms with centralized R\&D labs, we assigned that location to the innovation. For firms that had multiple R\&D locations, we took two further steps to identify the correct development location. The first step was to contact $R \& D$ managers of those firms to inquire about the correct $R \& D$ unit responsible for the innovation. Secondly, if the researchers failed to contact the R\&D managers, 
they carefully assessed the product-line specialization of each R\&D unit, and matched the innovation to the closest specialization area. Lastly, we discarded a very small number of remaining innovations for which we could not positively assign any location with high certainty from our sample.

\section{Methods}

A common method to construct indexes is to use principal component analysis (PCA), as it does not require the variables in the data to be normally distributed, which is usually the case when regional data is concerned and also a case in point here (the assumption was verified with ShapiroWilk test of normality). The basic idea behind PCA is to compress the information contained by several variables into a small number of principal components (PC) in a way which ensures that as little of the original information as possible is lost. PCA also calculates weights that express the impact that the original variables have on the PC. These weights are utilized in the construction of PC scores, which are then used to benchmark the regions innovative performance i.e. the scores comprise the innovation index.

A number of composite indexes where produced, using different combinations of the variables describing innovation: as mentioned above, the amount of R\&D expenditure and number of R\&D personnel were also analyzed separately for private and government sectors (Table 3). We made sure that the preconditions for successful PCA were fulfilled for individual indexes (see Jolliffe 2002; Tabachnick and Fidell 2007): firstly, the Bartlett tests of sphericity (BTS) were statistically significant, second, we confirmed that the Kaiser-Meyer-Olkin measures of sampling adequacy (KMO) were adequate (all indexes are over 0.6), and communalities and loadings to the principal component were sufficiently high (over 0.3 ). Only one principal component, the only one with a sufficiently high eigenvalue (E) over one, was produced per combination. 
Table 3 The composition of different innovation indexes and tests related to the preconditions of successful PCA

\begin{tabular}{|c|c|c|}
\hline & Communalities & Loadings \\
\hline \multicolumn{3}{|c|}{ Index all $(\mathrm{BTS}<0.001 ; \mathrm{KMO}=0.678 ; \mathrm{E}=3.259)$} \\
\hline - Patent applications & 0.754 & 0.869 \\
\hline - Patents granted & 0.832 & 0.912 \\
\hline - R\&D expenditure & 0.831 & 0.912 \\
\hline - R\&D personnel & 0.842 & 0.918 \\
\hline \multicolumn{3}{|c|}{ Index private $(\mathrm{BTS}<0.001 ; \mathrm{KMO}=0.680 ; \mathrm{E}=3.226)$} \\
\hline - Patent applications & 0.712 & 0.844 \\
\hline - Patents granted & 0.834 & 0.913 \\
\hline - Private R\&D expenditure & 0.813 & 0.902 \\
\hline - Private $R \& D$ personnel & 0.867 & 0.931 \\
\hline \multicolumn{3}{|c|}{ Index government $(\mathrm{BTS}<0.001 ; \mathrm{KMO}=0.615 ; \mathrm{E}=2.909)$} \\
\hline - Patent applications & 0.700 & 0.836 \\
\hline - Patents granted & 0.668 & 0.818 \\
\hline - Government R\&D expenditure & 0.779 & 0.883 \\
\hline - Government R\&D personnel & 0.762 & 0.873 \\
\hline
\end{tabular}

Next, we approached the question of feasibility of our measures through statistical testing. Spearman's rank correlation analysis was employed to analyze the connection between the different individual variables, innovation indexes and innovation counts (for examples of different correlation indexes see Chen and Popovich 2002). Furthermore, we divided the regions into three groups (the 25 highest, average and 25 lowest innovative profiles) according to their standings in the rankings produced by different measures. By applying standard cross tabulations with relevant statistical test (Cramer's V), we also tested how well the innovation indexes and individual indicators of innovation could group the different regions compared to grouping on the basis of innovation counts (for interpretation of Cramer's V see David and Sutton 2004). From the results of these tests we were able to deduce if the different indicators and indexes used here would produce similar rankings, which would be a sign of non-sensitivity of the measures (see Grupp and Schubert 2010).

\section{Results}

As stated above the first signs of non-sensitivity are given if the different ways to measure innovation would produce similar rankings. However, none of the tested measures has a near 
perfect correlation with innovation counts. The correlation is highest between the innovation index, including both private and government $\mathrm{R} \& \mathrm{D}$, and innovation counts (Table 4). Government R\&D statistics seem to be rather weakly associated with commercialized innovations, as expected. Private R\&D (both expenditures and personnel) and the index of the private sector correlate only slightly weaker with innovation counts than our overall innovation index. According to the correlation analysis, composite indexes seem to function (slightly) better as a benchmarking tool of regional innovative performance compared to the individual indicators. However, even though the disparities between the correlations of different measures are by and large quite marginal, the benchmarking rankings they produce are highly divergent nonetheless. The patents granted were also analyzed according to the eight IPC main sections. When analyzed independently per IPCsection, granted patents in Mechanical Engineering and Physics showed the highest correlation coefficients (Appendix). The only IPC-sections with weak or statistically insignificant correlation were those for Fixed Constructions as well as Chemistry and Metallurgy. Overall, the correlations are weaker than the aggregate patents granted variable, as many regions had zero values in specific IPC-sections. We therefore present the subsequent results in aggregate form.

Table 4 Spearman's correlation coefficients between regional innovation counts and other measures of innovation

\begin{tabular}{c|cccc}
\hline Direct innovation counts & Patent & Patents & R\&D spendings & R\&D spendings \\
& applications & granted & all & private \\
Correlation coefficient & $0.544^{*}$ & $0.558^{*}$ & $0.559^{*}$ & $0.630^{*}$ \\
\hline & R\&D spendings & R\&D personnel & R\&D personnel & R\&D personnel \\
& government & all & private & government \\
Correlation coefficient & $0.310^{*}$ & $0.513^{*}$ & $0.602^{*}$ & $0.288^{*}$ \\
\hline & Index & Index & Index & \\
& all & private & government & \\
\hline Correlation coefficient & $0.634^{*}$ & $0.630^{*}$ & $0.561^{*}$ & \\
\hline
\end{tabular}

* Significance value $<0.001$

Table 5 shows our 75 regions divided into the three groups (the 25 highest, average and 25 lowest innovative profiles) according to their standings in the rankings produced by different measures. From this, we can assess the correspondence between rankings based on different measures or indexes. When examining the cross-tabulations we get a different picture: only the overall and private innovation indexes as well as private $\mathrm{R} \& \mathrm{D}$ expenditure and patents granted have a modest 
association between them and the innovation counts measured with Cramer's V. Thus, divisions into groups of different innovative profiles with strict dividing lines should be used with caution, if they are to be used as a basis for policy making: a notion that is extremely important if e.g. division of development areas is discussed for the allocation of public support. With the measures used here, a region with only a small difference between its adjacent regions can be labelled more (or less) well-off than it actually 'deserves' to be. Contrary to correlation analysis, crosstabulations and Cramer's $\mathrm{V}$ tests seem to indicate that the best tool for benchmarking regional innovative performance vis-à-vis innovation counts would be the private innovation index, as it performs better when regions are divided into groups. However, also here, the differences are marginal. Furthermore, if the number of groups is increased to e.g. five, none of the used measures can be said to have even a modest association with innovation counts. Fig. 1 further highlights these issues as it represents the rankings of the top regions of Finland in terms of innovative performance (measured in overall and private innovation indexes and innovation counts). The biggest population centers of Finland, Helsinki and Tampere, do well on each of the measures. However, there is sizable variation even in the rankings of the other top regions.

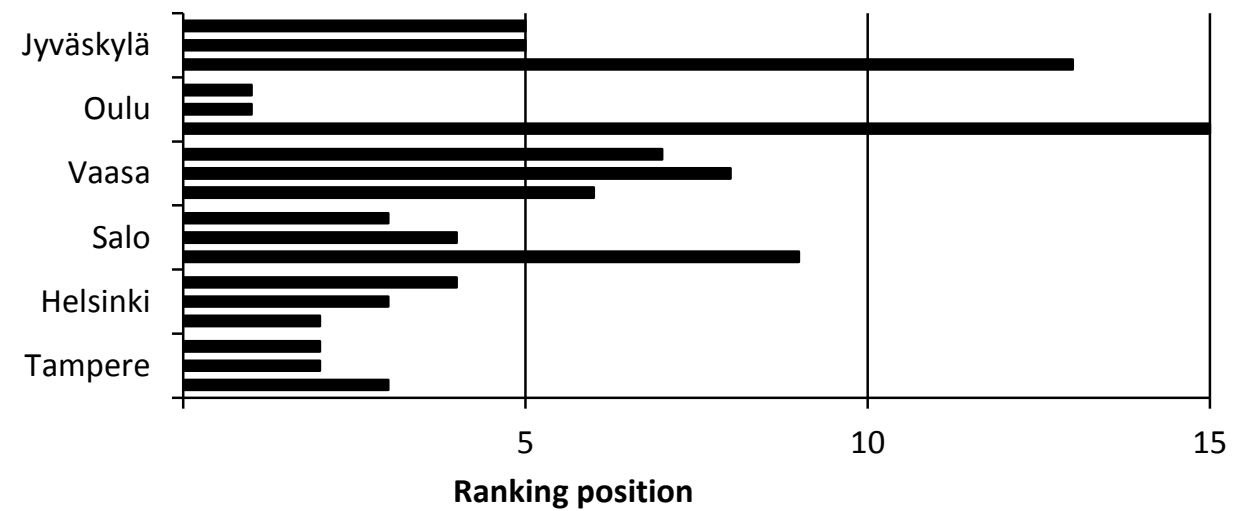

Fig. 1 Ranking of the most innovative regions in Finland (top = index private; middle = index all; bottom $=$ innovation counts) 
Table 5 Cross-tabulations and Cramer's V statistics

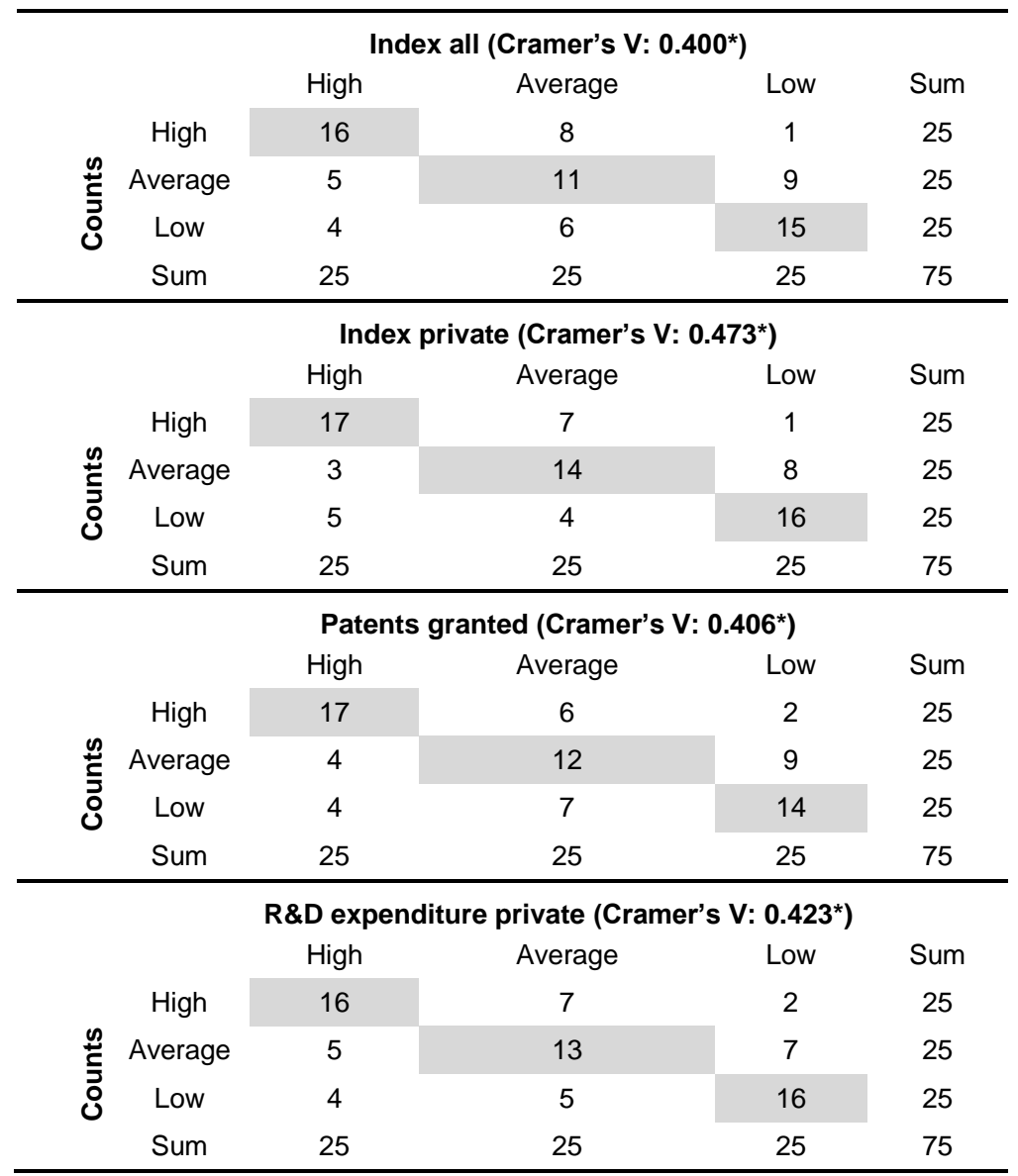

* Significance value $<0.001$

Previous literature has stressed that R\&D does not account for all the effort put in innovation and that prolific patenting does not necessarily manifest itself in equally high number of commercialized innovations. Also, from the analysis of this paper we can conclude that on the regional level, the link from $R \& D$ to patents and further to innovation is fuzzy.

\section{Conclusions}

The measurement of such a heterogeneous and complex issue as innovation is challenging. The use of proxy measures of innovation as benchmarking tools should be done with great care, as it has been shown in this paper, that different measures produce highly divergent rankings of regional innovative performance. Furthermore, although the produced overall and private innovation indexes perform (slightly) better, they cannot be claimed to be fully superior in relation to other indicators, rather they are marginally better. The problem lies in the linkages between the proxy measures and actual innovations: a good innovative capacity of a region does not 
necessarily lead to a high number of innovative outputs. None of the variables used here can be said to have a stable relation with each other. The 'path' to innovation is not simplistic rather it varies according to each innovation process. Some innovations are almost solely produced by investments in R\&D and they are also patented before they are introduced into the markets. On the other hand, not all innovations are created through traditional R\&D efforts, quite the contrary, and a significant amount of innovations are never patented. For example, the concept of 'open innovation' is an example of the highly divergent strategies for acquiring technological advantage (see e.g. Huizingh 2011). Conversely, not all R\&D efforts are successful and not all patented innovations are introduced to the markets. Also our finding that the linkages between patents and innovations as output differ across technological fields seems to suggest the divergent nature of innovation paths depending on the context to some extent.

As a practical recommendation one should consider more than one indicator or index when benchmarking regional innovative performance. Moreover, caution should be taken before drawing far-reaching policy conclusions depending on single measures as the linkages between innovation input- and output-indicators are fuzzy. For example, the growing amount of resources devoted to $\mathrm{R} \& \mathrm{D}$ does not produce an equal increase in patent and innovation statistics: the regions with highest $R \& D$ inputs are not unambiguously the ones with highest innovation output. Thus policies relying solely on the effects of $R \& D$ to heighten the regional innovative performance are not guaranteed to succeed. Especially, the direct connection between government funded R\&D and commercialized innovations seemed weak in our data. Nonetheless, our work has limitations. While our data includes both government and private $R \& D$ expenditures, this provides only limited insight in the position of science as a regional determinant of innovative activity. Future work could incorporate geospatial bibliometric data on regional scientific publications (e.g. Altvater-Mackensen et al. 2005). In addition, while we were able to show that our results do indeed vary by field of technology, we were unable to detect whether these differences are due to sectoral innovation characteristics, or are related to the sparseness of economic activity in many of our regions. Further research based on data with more observations per area and more equal density across areas would be needed to confront cross-classification more reliably. Relatedly, another limitation of our work is its confinement to the Finnish case. While LBIO data is only scarcely available, future work could benefit from including data from other economies. 


\section{Acknowledgements}

This work is partly funded by the Academy of Finland (project 127213). We acknowledge the financial support from VTT Technical Research Centre of Finland and the Finnish Funding Agency for Technology and Innovation (Tekes) that have enabled the construction of the SFINNO database. Finally, we are grateful for the anonymous reviewers' suggestions to improve the paper. Remaining errors are ours.

\section{References}

Acs, Z. (2002). Innovation and the growth of cities. Cheltenham: Edward Elgar Publishers.

Acs, Z., Anselin, L., \& Varga, A. (2002). Patents and innovation counts as measures of regional production of new knowledge. Research Policy, 31(7), 1069-1085.

Acs, Z., \& Audretsch, D. (1993). Analysing innovation output indicators: The US experience. In A. Kleinknecht \& D. Bain (Eds.), New concepts in innovation output measurement (pp. 1041). New York: Saint Martin’s Press.

Acs, Z., Audretsch, D., \& Feldman M. (1992). Real effects of academic research: Comment. The American Economic Review, 82(1), 363-367.

Acs, Z., \& Varga, A. (2002). Geography, endogenous growth and innovation. International Regional Science Review, 25(1), 132-148.

Altvater-Mackensen, N., Balicki, G., Bestakowa, L., Bocatius, B., Braun, J., et al. (2005). Science and technology in the region: The output of regional science and technology, its strengths and its leading institutions. Scientometrics, 63(3): 463-529.

Archibugi, D., \& Coco, A. (2005). Measuring technological capabilities at the country level: A survey and a menu for choice. Research Policy, 34(2), 175-194.

Archibugi, D., \& Pianta, M. (1996). Measuring technological change through patents and innovation surveys. Technovation, 16(9), 451-468.

Arundel, A. (2001). The relative effectiveness of patents and secrecy for appropriation. Research Policy, 30(4), 611-624.

Arundel, A., \& Kabla, I. (1998). What percentage of innovations are patented? Empirical estimates for European firms. Research Policy, 27(2), 127-141. 
Beard, T., Ford, R., Koutsky, T., \& Spiwak, L. (2009). A valley of death in the innovation sequence: An economic investigation. Research Evaluation, 18(5), 343-356.

Beneito, P. (2006). The innovative performance of in-house and contracted R\&D in terms of patents and utility models. Research Policy, 35(4), 502-517.

Booysen, F. (2002). An overview and evaluation of composite indices of development. Social Indicators Research, 59(2), 115-151.

Buesa, M., Heijs, J., \& Baumert, T. (2010). The determinants of regional innovation in Europe: A combined factorial and regression knowledge production function approach. Research Policy, 39(6), 722-735.

Buesa, M., Heijs, J., Martínez Pellitero, M., \& Baumert, T. (2006). Regional systems of innovation and the knowledge production function: The Spanish case. Technovation, 26(4), 463-472.

Camacho, J., \& Rodríguez, M. (2005). How innovative are services? An empirical analysis for Spain. The Service Industries Journal, 25(2), 253-271.

Carayannis, E., \& Provance, M. (2008). Measuring firm innovativeness: Towards a composite innovation index built on firm innovative posture, propensity and performance attributes. International Journal of Innovation and Regional Development, 1(1), 90-107.

Chen, P., \& Popovich, P. (2002). Correlation: Parametric and nonparametric measures. Quantitative Applications in the Social Sciences, 139.

Coad, A., \& Rao, R. (2008). Innovation and firm growth in high-tech sectors: A quantile regression approach. Research Policy, 37(4), 633-648.

Coombs, R., Narandren, P., \& Richards, A. (1996). A literature-based innovation output indicator. Research Policy, 25(3), 403-413.

Damanpour, F. (1991). Organizational innovation: A meta-analyses of effects of determinants and moderators. Academy of Management Journal, 34(3), 555-590.

David, M., \& Sutton, C. (2004). Social research: The basics. London: SAGE Publications.

de Bruijn, P., \& Lagendijk, A. (2005). Regional innovation systems in the Lisbon strategy. European Planning Studies, 13(8), 1153-1172.

Edwards, K., \& Gordon, T. (1984). Characterization of innovations introduced on the US market in 1982. Washington, DC: US Small Business Administration.

Fagerberg, J., \& Srholec, M. (2008). National innovation systems, capabilities and economic development. Research Policy, 37(9), 1417-1435. 
Fagerberg, J., \& Verspagen, B. (2009). Innovation studies - The emerging structure of a new scientific field. Research Policy, 38(2), 218-233.

Feeny, S., \& Rogers, M. (2003). Innovation and performance: Benchmarking Australian firms. The Australian Economic Review, 36(3), 253-264.

Gössling, T., \& Rutten, R. (2007). Innovation in regions. European Planning Studies, 15(2), 253 270.

Griliches, Z. (Ed.) (1984). $R$ and D, patents and productivity. Chicago: University of Chicago Press.

Grupp, H., \& Mogee, M. (2004). Indicators for national science and technology policy: How robust are composite indicators? Research Policy, 33(9), 1373-1384.

Grupp, H., \& Schubert, T. (2010). Review and new evidence on composite innovation indicators for evaluating national performance. Research Policy, 39(1), 67-78.

Gu, W., \& Tang, J. (2004). Link between innovation and productivity in Canadian manufacturing industries. Economics of Innovation and New Technology, 13(7), 671-686.

Hagedoorn, J., \& Cloodt, M. (2003). Measuring innovative performance: Is there and advantage in using multiple indicators? Research Policy, 32(8), 1365-1379.

Hall, B., Jaffe, A., \& Trajtenberg, M. (2005). Market value and patent citations. RAND Journal of Economics, 36(1), 16-38.

Hipp, C., \& Grupp, H. (2005). Innovation in the service sector: The demand for service-specific innovation measurement concepts and typologies. Research Policy, 34(4), 517-535.

Hollenstein, H. (1996). A composite indicator of firm's innovativeness: An empirical analysis based on survey data for Swiss manufacturing. Research Policy, 25(4), 633-645.

Huizingh, E. (2011). Open innovation: State of the art and future perspectives. Technovation, 31(1), 2-9.

Jaffe, A. (1989). Real effects of academic research. The American Economic Review, 79(5), 957970.

Jolliffe, I. (2002). Principal component analysis. New York: Springer.

Kaasa, A. (2009). Effects of different dimensions of social capital on innovative activity: Evidence from Europe at the regional level. Technovation, 29(3), 218-233.

Kleinknecht, A., van Montfort, K., \& Brouwer, E. (2002). The non-trivial choice between innovation indicators. Economics of Innovation and New Technology, 11(2), 109-121. 
Kline, S., \& Rosenberg, N. (1986). An overview of innovation. In R. Landau \& N. Rosenberg (Eds.), The positive sum strategy: Harnessing technology for economic growth (pp. 275-305). Washington, DC: National Academy Press.

Lepori, B., Barré, R., \& Filliatreau, G. (2008). New perspectives and challenges for design and production of S\&T indicators. Research Evaluation, 17(1), 33-44.

Lieberman, M. (1989). The learning curve, technology barriers to entry and competitive survival in the chemical processing industries. Strategic Management Journal, 10(5), 431-447.

Mäkinen, I. (2007). To patent or not to patent? An innovation-level investigation of the propensity to patent. VTT Publications, 646.

Mendonça, S., Pereira, T., \& Godinho, M. (2004). Trademarks as an indicator of innovation and industrial change. Research Policy, 33(9), 1385-1404.

Michel, J., \& Bettels, B. (2001). Patent citation analysis: A closer look at the basic input data from patent search reports. Scientometrics, 51(1), 185-201.

Molas-Gallart, J., \& Davies, A. (2006). Toward theory-led evaluation. American Journal of Evaluation, 27(1), 64-82.

Moon, H-S., \& Lee, J-D. (2005). A fuzzy set theory approach to national composite S\&T indices. Scientometrics, 64(1), 67-83.

Nelson, A. (2009). Measuring knowledge spillovers: What patents, licenses and publications reveal about innovation diffusion. Research Policy, 38(6), 994-1005.

OECD (1992). Oslo manual: Proposed guidelines for collecting and interpreting technological innovation data. Paris: OECD Publications.

OECD (2005). Oslo manual: Guidelines for collecting and interpreting innovation data. Paris: OECD Publications.

OECD (2011). OECD science, technology and industry scoreboard 2011. Paris: OECD Publications.

Palmberg, C., Leppälahti, A., Lemola, T., \& Toivanen, H. (1999). Innovations and industrial renewal in Finland - A new perspective. VTT Working Papers, 41.

Perez, C., \& Soete, L. (1988). Catching up in technology: Entry barriers and windows of opportunity. In G. Dosi, C. Freeman, R. Nelson, G. Silverberg \& L. Soete (Eds.), Technical change and economic theory (pp. 458-479). London: Pinter. 
Pinto, H. (2009). The diversity of innovation in the European Union: Mapping latent dimensions and regional profiles. European Planning Studies, 17(2), 304-326.

Pinto, H., \& Guerreiro, J. (2010). Innovation regional planning and latent dimensions: The case of the Algarve region. Annals of Regional Science, 44(2), 315-329.

Ratanawaraha, A., \& Polenske, K. (2007). Measuring the geography of innovation: A literature review. In K. Polenske (Ed.), The economic geography of innovation (pp. 30-59). Cambridge: Cambridge University Press.

Rothwell, R. (1992). Successful industrial innovation: Critical factors for the 1990s. $R \& D$ Management, 22(3), 221-238.

Rothwell, R., \& Gardiner, P. (1988). Re-innovation and robust designs: Producer and user benefits. Journal of Marketing Management, 3(3), 372-387.

Saisana, M., Saltelli, A., \& Tarantola, S. (2005). Uncertainty and sensitivity analysis techniques as tools for the quality assessment of composite indicators. Journal of the Royal Statistical Society. Series A, 168(2), 307-323.

Schmoch, U., \& Gauch, S. (2009). Service marks as indicators for innovation in knowledge-based services. Research Evaluation, 18(4), 323-335.

Schmookler, J. (1950). The interpretation of patent statistics. Journal of the Patent Office Society, 32(2), 123-146.

Schumpeter, J. (1934). The theory of economic development: An inquiry into profits, capital, credit, interest and the business cycle. New York: Oxford University Press.

Slaper, T., Hart, N., Hall, T., \& Thompson, M. (2011). The index of innovation: A new tool for regional analysis. Economic Development Quarterly, 25(1), 36-53.

Smith, K. (2005). Measuring innovation. In J. Fagerberg, D. Mowery \& R. Nelson (Eds.), The Oxford handbook of innovation (pp. 148-177). New York: Oxford University Press.

Tabachnich, B., \& Fidell, L. (2007). Using multivariate statistics. Boston: Pearson.

Tang, J., \& Le, C. (2007). Multidimensional innovation and productivity. Economics of Innovation and New Technology, 16(7), 501-516.

Unger, B. (2000). Innovation systems and innovative performance: Voice systems. Organization Studies, 21(5), 941-969.

van der Panne, G. (2007). Issues in measuring innovation. Scientometrics, 71(3), 495-507. 
van der Panne, G., \& van Beers, C. (2006). On the Marshall-Jacobs controversy: It takes two to tango. Industrial and Corporate Change, 15(5), 877-890.

Varga, A. (2006). The spatial dimension of innovation and growth: Empirical research methodology and policy analysis. European Planning Studies, 14(9), 1171-1186.

Zabala-Iturriagagoitia, J., Voigt, P., Gutiérrez-Gracia, A., \& Jiménez-Sáez, F. (2007). Regional innovation systems: How to assess performance. Regional Studies, 41(5), 661-672.

Appendix Spearman's correlation coefficients between regional innovation counts and patents granted by IPC main-sections

IPC-sections

\begin{tabular}{lc} 
A: Human necessities & $0.315^{\star}$ \\
B: Performing operations; Transporting & $0.466^{\star}$ \\
C: Chemistry; Metallurgy & 0.239 \\
D: Textiles; Paper & $0.425^{\star}$ \\
E: Fixed constructions & 0.079 \\
F: Mechanical engineering & $0.516^{\star}$ \\
G: Physics & $0.501^{\star}$ \\
H: Electricity & $0.350^{\star}$ \\
\hline
\end{tabular}

* Significance value $<0.001$ 